\title{
The impact of selected biofuels on the performance parameters of the Common Rail power system in the utility engine
}

\author{
Pawet Krzaczek ${ }^{1, *}$, Arkadiusz Rybak ${ }^{2}$, and Andrzej Bochniak ${ }^{3}$ \\ ${ }^{1}$ University of Life Sciences, Department of Power Engineering and Transportation, Głęboka 28, 20-612 Lublin, Poland \\ ${ }^{2}$ Lublin University of Technology, Faculty of Mechanical Engineering, Nadbystrzycka 36, 20-618 Lublin, Poland \\ ${ }^{3}$ University of Life Sciences, Department of Applied Mathematics and Computer Science, Głęboka 28, 20-612 Lublin, Poland
}

\begin{abstract}
The aim of the research was to determine the impact of biofuels from waste materials of plant and animal origin on the parameters of the common rail power supply system in the utility engine. The tests included identification of power system operation parameters in the whole load range of the tested engine, taking into account the limit and diagnostic parameters of the injectors operation. Then, for certain parameters, the engine injectors were tested on the test bench: injection pressure in the range of 25-135 $\mathrm{MPa}$, injection time in the range of 200-1600 $\mu \mathrm{s}$. In the tests, as reference fuel for testing injectors were used diesel fuel and three types of methyl esters of higher fatty acids: vegetable, animal and WCO origin. The measurements for individual fuels were made in the operating temperature range $30-60^{\circ} \mathrm{C}$. The tests have shown significant changes in the volume of the fuel injection rates depending on the fuel used. Particularly, visible changes concerned the power system operation parameters for high engine speeds and the maximum working pressure of the common rail system in the engine.
\end{abstract}

\section{Introduction}

Today, it is estimated that transport generates about $20 \%$ of global energy demand. Due to high energy efficiency, high torque, high energy density of fuel in the different means of transport, self-ignition internal combustion engines play a dominant role [1, 2]. This particularly applies to the use of internal combustion engines in heavy duty vehicles. In addition, the use of diesel engines makes it possible to use a wide range of fuels to supplement or replace diesel [3].

The growing, restrictive requirements for the emission of toxic exhaust components and the increase in requirements for improving the efficiency of diesel engines, also in the context of reducing $\mathrm{CO}_{2}$ emissions, necessitate the introduction of new design solutions (e.g. diesel particulate filters, various types of catalysts, use of high-pressure fuel systems) $[4,5]$ or the use of new combustion systems [6]. This causes complications in the construction of motors and significantly reduces the reliability of drive units, increases maintenance activities (e.g. for units with SCR system) [7], and consequently, leads to potential interruption of transport processes. In addition, the introduction of new constructional solutions entails a delay of several years in the exploitation practice of the vehicle and in some cases the need to adapt the transport infrastructure to them.

Regarding vehicles and means of transport in operation, it seems preferable, instead of implementing new construction solutions, to introduce fuels that have a significantly smaller impact on the environment than diesel $[1,8,9]$. The most commonly used fuels are methyl esters of higher fatty acids of various origins [10]. The most popular ones are first generation biofuels based on oils of edible plants (rapeseed [11], sunflower, soybean, or palm) [12], the use of which does not require significant modifications in usable or traction engines [13].

On the one hand, biofuels allow for the reduction in the emission of the toxic components of exhaust fumes, carbon monoxide, hydrocarbons or particulates (due to the oxygen content), and, on the other hand, to fulfill the indicative targets of individual countries regarding the use of renewable energy sources [2]. However, the level of energy demand makes it necessary to look for new sources of raw materials for the production of biofuels. The use of raw materials in the form of non-edible plant oils or waste oils (animal, frying) allows for the increase in the potential of liquid biofuels. However, fuels made from them often do not meet the requirements for fuels used in modern diesel engines, especially in common rail systems. In addition, the production of biofuels from a variety of raw materials causes a variable chemical composition of the obtained fuel and also involves changes in physical properties, especially lowtemperature ones. In the case of biofuels, an important parameter is their viscosity from the point of view of controlling the injection process. On the other hand, the chemical composition, especially oxygen content and energy value of fuel have significant impact on the fuel combustion process $[14,15,16]$.

The reasons mentioned for the introduction of biofuels of various origin resulted in undertaking research aimed

\footnotetext{
* Corresponding author: pawel.krzaczek@up.lublin.pl
} 
at assessing the impact of pure biofuels on the performance parameters of the common rail power system in the utility engine. The tests were based on an internal combustion engine, which is used in heavy road vehicles, farm tractors or industrial engines.

\section{Research focus}

The aim of the research was to determine the impact of biofuels from waste materials of plant and animal origin on the parameters of the common rail power supply system in the utility engine.

\section{Object and methods of research}

The tests included identification of the operating parameters of the John Deere JD 4045HF285 fuel system. The basic parameters of the tested engine are shown in Table 1.

Table 1. Specification of the tested engine.

\begin{tabular}{|l|l|}
\hline \multicolumn{1}{|c|}{ Parameter } & \multicolumn{1}{c|}{ Engine } \\
\hline Engine type/model & $\begin{array}{l}\text { automotive variable speed 4-stroke } \\
\text { engine/4045HF285 }\end{array}$ \\
\hline Application & $\begin{array}{l}\text { diesel truck, tractors, industrial } \\
\text { motors }\end{array}$ \\
\hline No. of cylinders & 4 \\
\hline Compression ratio & $19: 1$ \\
\hline Rated speed, rpm & 2400 \\
\hline Rated power, kW & $74 @$, 2400 rpm \\
\hline Rated torque, Nm & $353 @$, 1600 rpm \\
\hline Displacement, cc & 4530 \\
\hline Aspiration system & turbocharged without Intercooler \\
\hline Fuel delivery system & common rail \\
\hline Fuel Injection Pump & Denso HP3 \\
\hline $\begin{array}{l}\text { Maximum fuel pressure, } \\
\text { MPa }\end{array}$ & 105 \\
\hline $\begin{array}{l}\text { Minimum fuel pressure at } \\
\text { idle speed, MPa }\end{array}$ & 40 \\
\hline Injector type/model & CR/Denso 095000-6310 \\
\hline
\end{tabular}

The engine is equipped with a common-mode Denso power supply system and an electronic control system that allows for the reading and recording of fuel injection pressures in the system. The engine was mounted on a dynamometric test bench coupled with an electro-spin brake and Automex AMX data control and archiving system. In order to determine the fuel pressure level, the engine was loaded with a torque $T$ from $0 \mathrm{Nm}$ to full load, every $25 \mathrm{Nm}$ in the speed range $n$ of 1200 to $2400 \mathrm{rpm}$, every $100 \mathrm{rpm}$.

In the next step, the Denso CR injectors type 0950006310 were removed from the engine and mounted on the test stand for characteristics of injectors and common rail injection pumps. A detailed description of the test stand has been included in the works [17, 18].

The tests were conducted for reference fuel (Calibrol), commercial diesel oil and three biofuels in the form of methyl esters respectively: rapeseed oil - BIO 1, animal fats - BIO 2, plant waste cooking oil - BIO 3. The chemical composition and basic properties of the tested fuels are presented in Table 2 and 3.
Table 2. The chemical composition of the tested biofuels.

\begin{tabular}{|l|c|c|c|}
\hline $\begin{array}{c}\text { Common name of } \\
\text { faty acide methyl ester }\end{array}$ & BIO 1 & BIO 2 & BIO 3 \\
\hline Myristic C14:0 & - & - & 0,12 \\
\hline Palmitic C16:0 & 0,32 & 20,8 & 6,51 \\
\hline Palmitoleic C16:1 & 4,1 & - & 0,35 \\
\hline Stearic C18:0 & 1,58 & 6,3 & 3,7 \\
\hline Oleic C18:1 & 62,04 & 44,6 & 63,7 \\
\hline Linoleic C18:2 & 19,81 & 15,7 & 21,27 \\
\hline Linolenic C18:3 & 8,97 & 0,85 & 1,2 \\
\hline Arachidic C20:0 & 0,77 & - & 0,27 \\
\hline Eicosenoic C20:1 & 1,16 & - & 0,65 \\
\hline Others & 1,25 & 11,75 & 2,23 \\
\hline
\end{tabular}

Table 3. Property of the tested fuels.

\begin{tabular}{|c|c|c|c|c|c|}
\hline Fuel property & $\overline{0}$ & $\stackrel{n}{0}$ & $\stackrel{m}{0}$ & 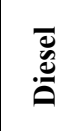 & 完 \\
\hline Density@30 $\mathrm{C}, \mathrm{kg} / \mathrm{m}^{3}$ & 870,8 & 862,8 & 875,0 & 832,3 & 815,0 \\
\hline 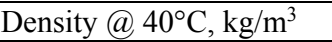 & 865,2 & 856,0 & 868,4 & 825,1 & 807,6 \\
\hline Density@ $@ 50^{\circ} \mathrm{C}, \mathrm{kg} / \mathrm{m}^{3}$ & 858,4 & 849,3 & 861,8 & 817,8 & 800,2 \\
\hline Density@60 $\mathrm{C}, \mathrm{kg} / \mathrm{m}^{3}$ & 851,7 & 842,6 & 855,2 & 810,6 & 792,9 \\
\hline Viscosity@30 $30^{\circ} \mathrm{C} \mathrm{mm}^{2} / \mathrm{s}$ & 5,54 & 7,09 & 6,07 & 3,65 & 3,10 \\
\hline Viscosity@40ㄷ, mm²/s & 4,43 & 5,45 & 4,80 & 2,97 & 2,55 \\
\hline Viscosity @ $50^{\circ} \mathrm{C}, \mathrm{mm}^{2} / \mathrm{s}$ & 3,63 & 4,49 & 3,94 & 2,5 & 2,14 \\
\hline Viscosity @ $60^{\circ} \mathrm{C}, \mathrm{mm}^{2} / \mathrm{s}$ & 3,05 & 3,73 & 3,30 & 2,15 & 1,81 \\
\hline
\end{tabular}

The density of fuel was determined by the hydrometer in accordance with PN-EN ISO 3675 at $30,40,50,60^{\circ} \mathrm{C}$. The kinematic viscosity of the studied fuels was determined by capillary according to PN-EN ISO 3104 at temperatures of $30,40,50$ and $60^{\circ} \mathrm{C}$ (Table 3). The composition of the various methyl esters was determined in accordance with PN-EN 14103 (Table 2), due to the significant impact of different types of esters on the physicochemical property of fuel.

All fuels were tested at temperatures from 30 to $60^{\circ} \mathrm{C}$, at fuel pressures ranging from 25 to $135 \mathrm{MPa}$. Injectors opening time varied from 200 to $1600 \mu \mathrm{s}$. Therefore, the extreme values of injection parameters were also checked, which were determined by the manufacturer in points $\mathrm{P} 1$ (injection pressure $25 \mathrm{MPa}$, injector opening time $600 \mu \mathrm{s}$ ) and $\mathrm{P} 2$ (injection pressure $135 \mathrm{MPa}$, injector opening time $850 \mu \mathrm{s})$. On the basis of the obtained fuel injection quantities for individual parameters (pressure and injection time), the active flow cross section was calculated. For this purpose, the effective injection time was determined as the ratio of the amount of fuel injected at the test stand to the time of injection. The effective time was calculated as the difference between the injector coil feeding time and the time determined by extrapolation to the ordinates of the curve formed on the basis of the injection values at a given point at constant pressure. The active flow cross section identified is directly proportional to the volumetric flow rate of the injected fuel and inversely proportional to the square root of the ratio between the value of twice the product of the differential pressure before and after the injector and the density value of the tested fuel. A detailed definition of the active flow cross section is presented in [17]. 


\section{Test results}

\subsection{Injection pressure of the fuel supply system}

The obtained values of fuel injection pressure at different rotational speeds allowed us to distinguish between three characteristic curves of pressure curves as a function of load, which were presented in Figures 1 to 3.

In Fig. 1 for speeds of 1200-1400 rpm it can be seen that the fuel pressure rises from about 70 to $90 \mathrm{MPa}$ at $150 \mathrm{Nm}$, and then remains at this level. Changes in the course of the pressure curve can be observed at a rotational speed of $1500 \mathrm{rpm}$. For $50 \mathrm{Nm}$ load the pressure increases slightly, then decreases by $10 \mathrm{MPa}$ at $200 \mathrm{Nm}$, after which it gradually increases to the level of $90 \mathrm{MPa}$.

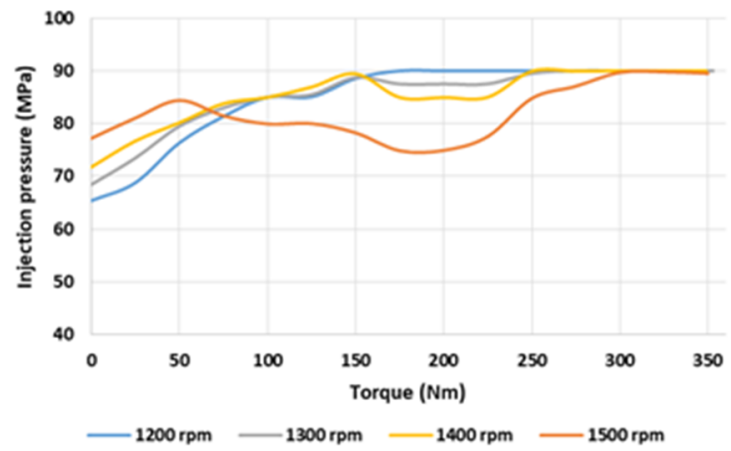

Fig. 1. Fuel injection pressure in the fuel supply system at 1200-1500 rpm.

The next group of curves is shown in Fig. 2 and refers to the rotational speed from 1600 to $1900 \mathrm{rpm}$, for which the curves have a similar character. Initially, the pressure drops from $85-88 \mathrm{MPa}$ to the local minimum at a load of $150 \mathrm{Nm}$, which ranges from $50 \mathrm{MPa}$ to $70 \mathrm{MPa}$. Then the pressure increases to $75-88 \mathrm{MPa}$ at maximum load. It should be noted that the tested engine acquires maximum torque at a speed of $1600 \mathrm{rpm}$, for which the lowest fuel injection pressure level has been recorded.

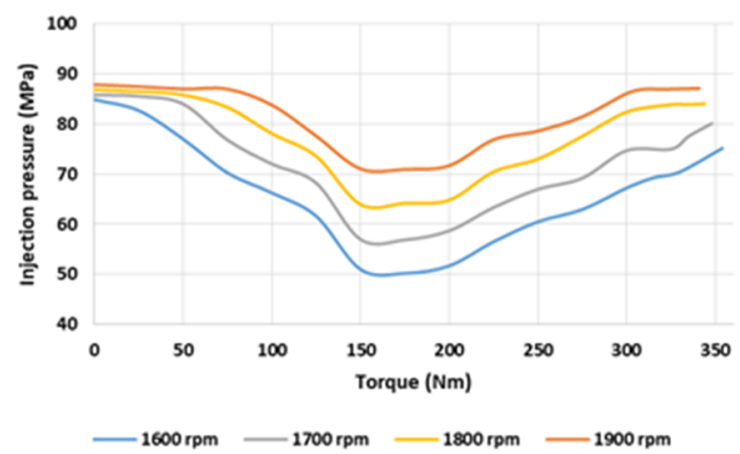

Fig. 2. Fuel injection pressure in the fuel supply system at 1600-1900 rpm.

The third group comprises the pressure curves for speeds from 2000 to $2400 \mathrm{rpm}$ (Fig. 3), which have a relatively flat course. The initial injection pressure is around $90 \mathrm{MPa}$. The lowest pressure values were at 2000 rpm, where the pressure drops to $78 \mathrm{MPa}(150 \mathrm{Nm})$, after which it increases to $90 \mathrm{MPa}$. The highest fuel pressure values correspond to the rated speed of the engine. In this case, the pressure course is a variable characteristic, it increases to $100 \mathrm{MPa}$, then drops to $95 \mathrm{MPa}$ and at full load again increases to a maximum pressure of $105 \mathrm{MPa}$.

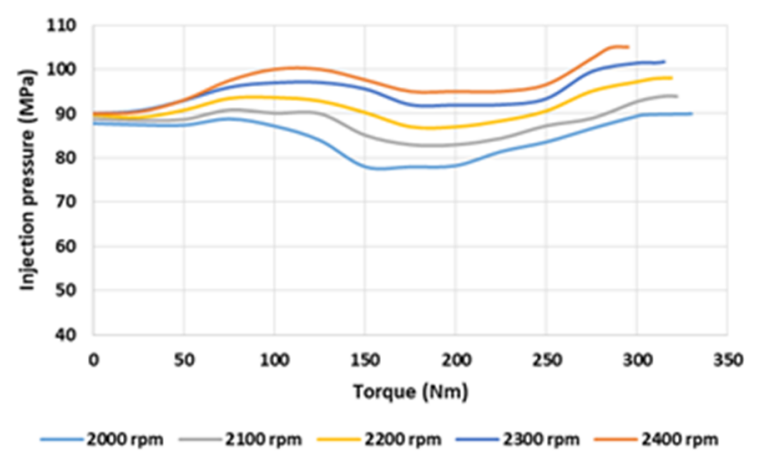

Fig. 3. Fuel injection pressure in the fuel supply system at 2000-2400 rpm.

Fig. 4 shows the dependence of the injection pressure on the rotational speed at zero load and for full engine load. In the absence of a load, the injection pressure increases with the increase of the rotational speed, the fastest being between 1300 and $1600 \mathrm{rpm}$. At full load, the injection pressure does not change to $1500 \mathrm{rpm}$ and is about $90 \mathrm{MPa}$, then it decreases to a minimum of $74 \mathrm{MPa}$ at $1600 \mathrm{rpm}$, after which it increases linearly to $105 \mathrm{MPa}$ at $2400 \mathrm{rpm}$.

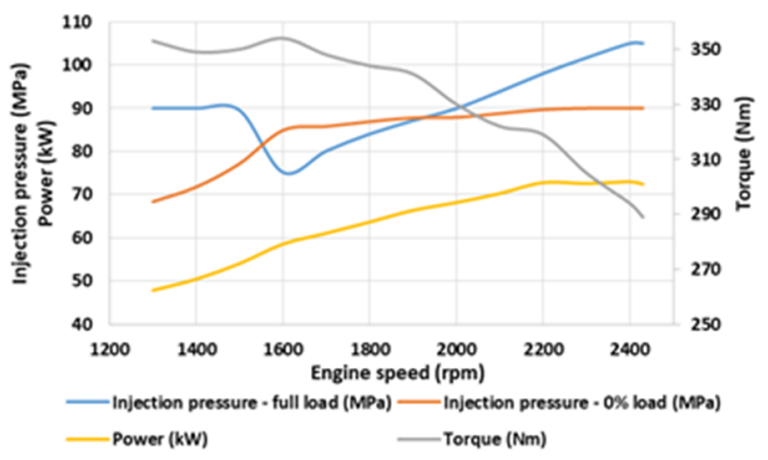

Fig. 4. Injection pressure, power output and torque characteristics in the function of engine revolutions at maximum load and idle speed.

Analyzing the entire working area of the engine, it can be concluded that the injection pressure varies with changes in the engine load in the range of 50 to $105 \mathrm{MPa}$. It should be pointed out that the minimum injection pressure for a given speed corresponded to the load, at which the air pressure generated by the turbocharger increases rapidly. For the minimum idling speed $(800 \mathrm{rpm})$ the injection pressure was $40 \mathrm{MPa}$, therefore the injection pressure in the range of 40 to $100 \mathrm{MPa}$ was taken into account when analyzing the discharge coefficient.

\subsection{The active flow cross section}

The tested fuels differed significantly in chemical composition and physical properties (Tables 2 and 3). The fuels used in the research represent the most popular types of raw materials for the production of biofuels, i.e. 
1 - generation biofuel vegetable oils - BIO 1, technical animal fats - BIO 2, waste cooking oil - BIO 3. Certain values of density, viscosity or heat of combustion are close to those described in the literature $[16,19]$. The lowest density and the highest viscosity was noted for BIO 2 biofuel. In contrast, the highest density and calorific value was found for BIO 3 frying oil. The obtained physical parameters result directly from the chemical composition of the fuel $[16,20]$. In addition, during tests it was found out that animal fuels have a high pour point, in the case of BIO 2 the blocking temperature of the cold filter was $11^{\circ} \mathrm{C}$. Analogous results for biofuels of animal origin were obtained in $[16,18,19,20]$. This parameter is the main obstacle to the use of clean biofuels during the actual operation of internal combustion engines.

Fig. 5 shows the size of the fuel dose at the diagnostic points specified by the manufacturer for the tested injectors. The parameters of point $\mathrm{P} 1$ correspond to the moment of opening the injector, while point P2 determines the maximum injection pressure provided for he tested injector type. The differences in the amount of reference fuel, diesel oil and biofuels tested by the injector are clearly visible, especially in P2 point. However, all injection volume values are within the range specified by the manufacturer, i.e. for $\mathrm{P} 1$ points they are $3.2 \pm 1 \mathrm{~mm}^{3}$ and for $\mathrm{P} 2-60 \pm 4 \mathrm{~mm}^{3}$. Taking into account the viscosity of fuels (Table 3 ), there was a clear dependence of the fuel doses (Fig. 5) on this parameter.

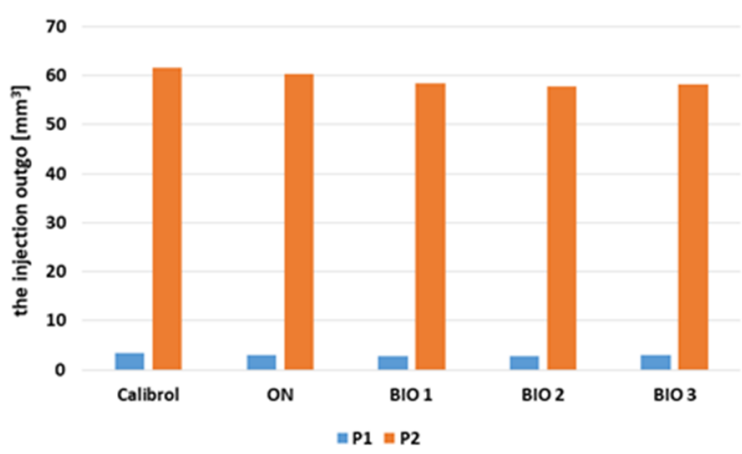

Fig. 5. Amount of fuel injected at diagnostic points.

In Fig. 6, the calculated active flow cross section at $30^{\circ} \mathrm{C}$ increases from 40 to $80 \mathrm{MPa}$ for all fuels, in which case the value of the coefficient is slightly higher for diesel fuel. For diesel and BIO 1, the factor reaches the maximum at $80 \mathrm{MPa}$, after which it is lower, especially for diesel. The maximum values for BIO 2 and BIO 3 are shifted by $20 \mathrm{MPa}$. This is especially evident for fuel of animal origin.

Due to the low temperature CFPP for $\mathrm{BIO} 2$ no measurements below $30^{\circ} \mathrm{C}$ were taken, it can be assumed that it corresponds to the engine heating phase and any correction of the injection parameters should be introduced for points with pressures above $80 \mathrm{MPa}$, i.e. for low and high engine loads.

The comparison of the active flow cross section curves depending on the injection pressure (Fig. 7) for the fuel temperature of $40^{\circ} \mathrm{C}$ was found to be similar to those in Fig. 6. The local maximum of the coefficient does not change, but the differences in the coefficient value increase above $60 \mathrm{MPa}$. The lowest values were recorded for biofuel BIO 2, while for pressure $100 \mathrm{MPa}$ for diesel oil. Since the fuel temperature of $40^{\circ} \mathrm{C}$ corresponds to low and medium loads, e.g. during transport work, correction of injection maps should be introduced for pressures above $60 \mathrm{MPa}$, and its variable size associated with the increase of pressure, especially at high engine load.

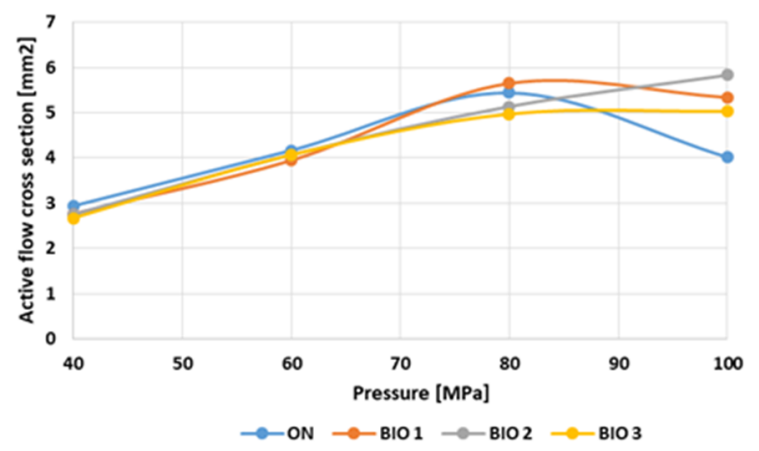

Fig. 6. Simile of the active flow cross sections of tested fuels at $30^{\circ} \mathrm{C}$.

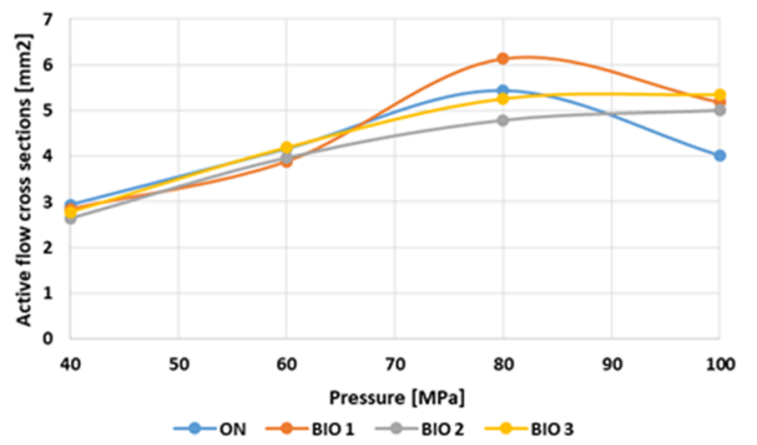

Fig. 7. Simile of the active flow cross sections of tested fuels at $40^{\circ} \mathrm{C}$.

An increase in fuel temperature of up to $50^{\circ} \mathrm{C}$ corresponds to medium and long-term engine operation conditions. In this case, the active flow cross section (Fig. 8) in the range of 60 to $80 \mathrm{MPa}$ is clearly higher for diesel and its maximum is shifted between 60 and $80 \mathrm{MPa}$. Moreover, above this point the coefficient for other fuels is higher, especially for BIO 1 fuel, which reaches its maximum again at $80 \mathrm{MPa}$. The coefficients for BIO 2 and BIO 3 are similar and reach a maximum at $100 \mathrm{MPa}$. At this temperature, the correction of the injection parameters should cover the entire tested pressure range, but their changes should be of a different nature.

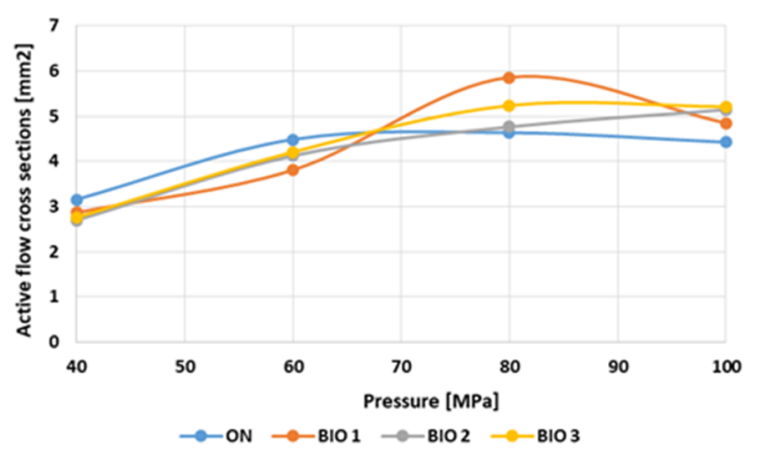

Fig. 8. Simile of the active flow cross sections of tested fuels at $50^{\circ} \mathrm{C}$. 
In the research at $60^{\circ} \mathrm{C}$, there were clear differences in the active flow cross section for diesel and all biofuels in the pressure range of 40 to $80 \mathrm{MPa}$ (Fig. 9). It should be pointed out that this is an area where there is an increase in turbocharger efficiency for medium rotational speeds and medium loads. In addition, in this pressure range, the entire load characteristic for the maximum torque speed is included. Therefore, when the motor is used for a long time with high thermal loads (high ambient temperature, long-lasting operation at almost full load) it requires adjustment of the controller settings, especially at pressures of $60 \mathrm{MPa}$ and $100 \mathrm{MPa}$.

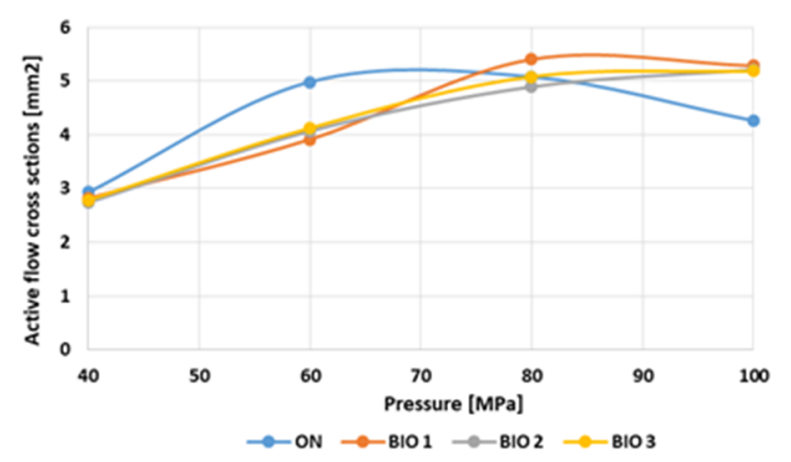

Fig. 9. Simile of the active flow cross sections of tested fuels at $60^{\circ} \mathrm{C}$.

\section{Conclusion}

The engine tests carried out on the dynamometric bench allowed us to determine the scope of the fuel supply system depending on the load and rotational speed. It was found out that fuel operating pressures range from 40 to $105 \mathrm{MPa}$, the value of which is significantly lower than the pressure levels tested in the literature $[21,22]$. It has been shown that for medium loads and high level of engine recharging, fuel pressure is reduced even to 50 $\mathrm{MPa}$ for the maximum torque speed.

Analyzing the calculated active flow cross section it was concluded that the differences in its value for diesel oil and individual biofuels increase with the temperature of the examined fuel. For temperatures of 30 and $40^{\circ} \mathrm{C}$, clear differences in the value of the coefficient occur above $80 \mathrm{MPa}$, which is related to the need to adjust the injection parameters for biofuels. Further increase of fuel temperature to 50 or $60^{\circ} \mathrm{C}$ deepens the differences in the coefficient for diesel oil and biofuels within the whole range of the power system operation, which is from 40 to $100 \mathrm{MPa}$.

In addition, it was found out that for BIO 1 fuel above $80 \mathrm{MPa}$, the active flow cross section has a higher value than for diesel fuel. However, for BIO 2 and BIO 3 fuels, this is the case only at $100 \mathrm{MPa}$.

\section{References}

1. K. Duda, S. Wierzbicki, M. Śmieja, M. Mikulski, Comparison of performance and emissions of a CRDI diesel engine fueled with biodiesel of different origin, Fuel, 212, 202-222 (2018)
2. S. Mishra, K. Anand, S. Santhosh, P. Mehta, Comparison of biodiesel fuel behavior in a heavy duty turbocharged and a light duty naturally aspirated engine, Applied Energy, 202, 459-470 (2017)

3. B. Sajjadi, A. Raman, H. Arandiyan, A comprehensive review on properties of edible and non-edible vegetable oil-based biodiesel: Composition, specifications and prediction models, Renewable and Sustainable Energy Reviews, 63, 62-92 (2016)

4. H. Howa, H. Masjuki, M. Kalam, H. Teoh, Influence of injection timing and split injection strategies on performance, emissions, and combustion characteristics of diesel engine fueled with biodiesel blended fuels, Fuel, 213, 106-114 (2018)

5. S. Ren, B. Wang, J. Zhang, Z. Wang, J. Wang, Application of dual-fuel combustion over the full operating map in a heavy duty multi-cylinder engine with reduced compression ratio and diesel oxidation catalyst, Energy Conversion and Management, 166, 1-12 (2018)

6. J. Hunicz, A. Tmar, P. Krzaczek, Effects of mixture stratification on combustion and emissions of boosted controlled auto-ignition engines, Energies, 10, 2172 (2017)

7. W. Urzędowska, Z. Stępień, Prediction of threats caused by high FAME diesel fuel blend stability for engine injector operation, Fuel Processing Technology, 142, 403-410 (2016)

8. G. Edara, Y. Murthy, P. Srinivas, J. Nayar, M. Ramesh, Effect of cooled EGR on modified light duty diesel engine for combustion, performance and emissions under high pressure split injection strategies, Case Studies in Thermal Engineering, 12, 188-202 (2018)

9. L. Lešnik, I. Biluš, The effect of rapeseed oil biodiesel fuel on combustion, performance, and the emission formation process within a heavy-duty DI diesel engine, Energy Conversion and Management, 109, 140-152 (2014)

10. C. Hayes, D. Burgess, J. Manion, Combustion pathways of biofuel model compounds: A review of recent research and current challenges pertaining to first-, second-, and third-generation biofuels, Advances in Physical Organic Chemistry, 49, 103-187 (2015)

11. G. Zając, W. Piekarski, P. Krzaczek, Comparison of an effect of FAME and FAEE addition to diesel fuel on energetic parameters of an engine, TEKA Kom. Mot. i Energ. Rol. - OL PAN, 8a, 217-223 (2008)

12. M. Bhuiya, M. Rasul, M. Khan, N. Ashwath, A. Azad, M. Hazrat, Prospects of 2 nd generation biodiesel as a sustainable fuel - Part2: Properties, performance and emission characteristics, Renewable and Sustainable Energy Reviews, 55, 1129-1146 (2016)

13. V. Goel, N. Kumar, P. Singh, Impact of modified parameters on diesel engine characteristics using biodiesel: A review. Renewable and Sustainable Energy Reviews, 82, 2716-2729 (2018) 
14. S. Slavinskas, G. Labeckas, T. Mickevicius, Experimental study on injection characteristics of diesel and biodiesel fuel blends with common-rail injection system, Engineering for rural development, Jelgava, 2134-2140 (2018)

15. M. Das, M. Sarkar, A. Datta, A. Santra, Study on viscosity and surface tension properties of biodieseldiesel blends and their effects on spray parameters for CI engines, Fuel, 220, 769-779 (2018)

16. E. Giakoumis, A statistical investigation of biodiesel physical and chemical properties, and their correlation with the degree of unsaturation. Renewable Energy, 50, 858-878 (2013)

17. A. Rybak, M. Gęca, P. Krzaczek, A. Mazanek, Determination of common rail injector flow characteristics with the use of diesel and biodiesel fuels, Journal of KONES, 23(4), 443-450 (2016)

18. A. Rybak, J. Hunicz, P. Krzaczek, W. Golimowski, D. Marcinkowski, Effect of different biofuels on common rail injector flow rate, Combustion Engines, 171(4), 39-43 (2017) DOI: 10.19206/CE-2017-407.

19. D. Marcinkowski, B. Rukowicz, W. Golimowski, M. Czechlowski, P. Krzaczek, W. Piekarski, Effect of selected depressants on cold filter plugging point for methyl esters obtained from transesterification of waste vegetable and animal fats, Przem. Chem, 96(9), 1927-1930 (2017), DOI: 10.15199/62.2017.9.22

20. N. Kumar, S. Varun, R. Chauhan, Performance and emission characteristics of biodiesel from different origins: A review, Renewable and Sustainable Energy Reviews, 21, 633-658 (2013)

21. L. Duan, S. Yuan, L. Hu, W. Yang, J. Yu, X. Xia, Injection performance and cavitation analysis of an advanced $250 \mathrm{MPa}$ common rail diesel injector, International Journal of Heat and Mass Transfer, 93, 388-397 (2015)

22. J. Bergthorson, M. Thomson, A review of the combustion and emissions properties of advanced Transportation biofuels and their impact on existing and future engines, Renewable and Sustainable Energy Reviews, 42, 1393-1417 (2015) 